\title{
An advance directive programme in nursing homes reduced health services use without affecting patient satisfaction
}

Molloy DW, Guyatt GH, Russo R, et al. Systematic implementation of an advance directive program in nursing homes. A randomized controlled trial.JAMA 2000 Mar 15;283:1437-44.

QUESTION: What is the effectiveness of systematic implementation of an advance directive programme in nursing homes?

\section{Design}

Randomised \{allocation concealed*\}†, \{blinded (patients) $\} \dagger, *$ controlled trial with 18 months follow up.

Setting

6 nursing homes in Ontario, Canada, with $>100$ residents each.

\section{Patients}

1292 patients who were nursing home residents.

\section{Intervention}

6 nursing homes were matched in pairs on key characteristics, and within each pair, each home was randomised to either an advance directive programme (3 intervention homes, 636 patients) or to usual policies of advance directives ( 3 control homes, 656 patients). The intervention homes used an advance directive programme called Let Me Decide (LMD), which consisted of healthcare choices related to life threatening illness, cardiac arrest, and nutrition. The LMD advance directive programme involved educating hospital and nursing home staff, patients, and families about advance directives. Head nurses on each ward classified patients as being mentally competent, incompetent, or "otherwise"; competent patients and next of kin of incompetent patients had the choice of completing the LMD advance directive. Residents who were rated as "otherwise" took the Mini-Mental State Examination; those who scored $\geqslant 16$ were given the LMD, and the LMD was provided to next of kin of those who scored $\leqslant 15$.

\section{Main outcome measures}

Source of funding: Agency for Healthcare

Research and Quality.

For correspondence: Dr D W Molloy, Geriatric Research Group, Hamilton Health Sciences Corporation, McMaster

University, 71

Concession Street,

Hamilton, Ontario

L8V 1C3, Canada. Fax

$+19055755121$

A modified version of

this abstract and

commentary also

appears in

Evidence-Based

Nursing.
Patient and family self reported satisfaction with health care and healthcare use. All costs were reported in Canadian dollars.

\section{Main results}

527 intervention home (83\%) and 606 control home (92\%) patients or their family members agreed to participate; 444 intervention home $(70 \%)$ and 374 control home (57\%) patients completed advance directives. Intervention homes had lower mean per patient number of admissions to hospital $(0.27 v 0.48, \mathrm{p}=0.001)$ than control homes, fewer hospital days (2.61 v 5.86, $\mathrm{p}=0.01)$, lower hospital costs $(\$ 1772$ v $\$ 3869$, $\mathrm{p}=0.003$ ), and lower total healthcare and implementation costs $(\$ 3490 v \$ 5239, \mathrm{p}=0.013)$. Intervention home and control home patients did not differ for satisfaction with health care or rate of death $(24 \% v 28 \%$, $\mathrm{p}=0.20)$.

\section{Conclusion}

Systematic implementation of an advance directive programme in nursing homes reduced use and costs of healthcare services without affecting patient satisfaction.

*See glossary.

$\dagger$ Information provided by author.

\section{COMMENTARY}

Molloy et al have made a commendable effort to determine the effects of systematically pursuing the implementation of advance directives by nursing home residents. Healthcare providers in the nursing homes and hospitals were alerted to the advance directives. The study showed that using advance directives led to less use of hospitals (with the associated cost savings) without adverse outcomes on patient satisfaction or mortality.

Teno, ${ }^{1}$ an investigator in the Study to Understand Prognoses and Preferences for Outcomes and Risks of Treatments (SUPPORT), praises Molloy $e$ t al for their well conducted study and promising results. She points out, however, that the data presented are insufficient to conclude that the directives that were implemented provided adequate palliation if the decision was not to admit to hospital. Other outcomes could have been considered, such as quality of life rather than patient satisfaction.

Furthermore, although 90 of the directives were completed by patients $(49 \%$ of those interested and deemed capable), families of patients who were "mentally incompetent" (78\% of those interested) completed 305 directives Choices by patients were similar to those made by their families. Previous studies, however, have shown that patient values for poor health are greater than anticipated by their families, and the value of advance directives completed by family members has been questioned. ${ }^{2}$

Perhaps the most interesting finding is that with a systematic educational effort, patients, their families, and healthcare providers can be made more aware of the many management options available, even when technology intensive interventions other than cardiopulmonary resuscitation are no longer desired. This awareness can be achieved without excessive cost.

Claudia Beghe, MD University of South Florida Tampa, Florida, USA

1 Teno JM. Advance directives for nursing home residents: achieving compassionate, competent, cost-effective care JAMA 2000;283:1481-2.

2 Tsevat J, Cook EF, Green ML, et al. Health values of the seriously ill. SUPPORT Investigators. Ann Intern Med 1995; 122:514-20. 